\title{
Mutual learning as a resource for research design
}

\author{
Toni Robertson, Tuck W Leong, Jeannette Durick and Treffyn Koreshoff \\ Faculty of Engineering and Information Technology \\ University of Technology, Sydney \\ \{Toni.Robertson,TuckWah.Leong,Jeannette.Durick\}@uts.edu.au \\ Treffyn.J.Koreshoff@student.uts.edu.au
}

\begin{abstract}
Mutual learning processes provide the context for this paper. We reflect on the early research design process of an ongoing project that is investigating the potential contributions of the Internet of Things (IoT) to ageing well. While mutual learning is assumed and embedded in Participatory Design tools and methods, it was only when we explicitly used mutual learning processes, as a resource in the research design of the project, that we could make clear and accountable decisions about how to proceed. The paper ends with a reaffirmation of the importance of mutual learning processes in Participatory Design, noting the opportunities, even imperatives, for foregrounding mutual learning processes in the design of IoT applications.
\end{abstract}

\section{Author Keywords}

Mutual learning, ageing well, domestic technologies, Internet of Things, IoT

\section{ACM Classification Keywords}

H5.m. Information interfaces and presentation (e.g., HCI): Miscellaneous.

\section{INTRODUCTION}

A key impetus behind the Scandinavian tradition of Participatory Design was the recognition that people, who were not professional technology designers, were unable to actively participate in designing technologies they might use because they lacked knowledge about what technologies-that were yet to exist-could offer them (eg Greenbaum and Kyng 1991; Simonsen and Robertson 2013). Many of the accounts of, and reminiscences about, early Participatory Design projects have a great deal to say about the mutual learning processes embedded in them, stressing the need for users and developers to learn together about possible and useful technology solutions (Bjerknes and Bratteteig 1988; Bødker 1988; Kyng 1988; Greenbaum and Kyng, 1991; Bratteteig 1997; Kensing and Greenbaum 2013). These days mutual learning remains a core commitment of Participatory Design and one of its key differentiators from User-Centred Design and other human-centred approaches. It is generally expressed as participants and designers learning from and about each others' expertise. That is, designers learn from

\footnotetext{
Permission to make digital or hard copies of all or part of this work for personal or classroom use is granted without fee provided that copies are not made or distributed for profit or commercial advantage and that copies bear this notice and the full citation on the first page. Copyrights for components of this work owned by others than ACM must be honored. Abstracting with credit is permitted. To copy otherwise, or republish, to post on servers or to redistribute to lists, requires prior specific permission and/or a fee. Request permissions from Permissions@acm.org.

PDC '14 Companion, October 06 - 10 2014, Windhoek, Namibia Copyright 2014 ACM 978-1-4503-3214-9/14/10 ..\$15.00 http://dx.doi.org/10.1145/2662155.2662181
}

the participants about their experiences, practices and situations, and participants learn from the designers about potential technological options and how these can be provided. Everyone involved learns more about technology design.

Mutual learning is supported by embedding the design process in the practices of the participants and by the use of various design tools and techniques, such as Future Workshops, design games and the development of prototypes, so that participants can experience something of how emerging designs may effect their everyday activities. The argument is that a process of mutual learning for both designers and users can enable participants to envisage future technologies and the practices in which they can be embedded (eg Greenbaum and Kyng, 1991; Simonsen and Robertson 2013). The political rationale is that mutual learning enables those, who would otherwise lack the power and resources, to genuinely participate in the design process, and to find and develop an effective voice in the shaping of their future activities and environments. The pragmatic rationale, one of the defining epistemological claims of Participatory Design, is that the design knowledge developed through mutual learning processes leads to better outcomes because of the multiple voices and perspectives engaged the mutual learning process (eg Kensing and Blomberg 1998; Robertson and Simonsen 2013). Indeed, as Kensing and Greenbaum (2013) remind us, "Equalizing power relations and mutual learning are both a motivation and an outcome of the Participatory Design heritage" (p. 21).

Revisiting and reaffirming mutual learning and the setting up of mutual learning processes provides the context for this paper. In it we reflect on the early research design process of an ongoing project that is investigating the potential contributions of the Internet of Things (IoT) to ageing well. The motivation for the project is that the Participatory Design of IoT applications, for the domestic environments of ageing people, can support their engagement in design and their capacities to envisage how the IoT could fit their own specific physical, social and emotional requirements for ageing well. In the following section we provide some background to the project that grounds a brief account of its early iterations and challenges as we sought to understand what we actually needed to learn about each other, how we would learn it and when we would know enough to proceed to the next stages of the design process (Bratteteig 1997). We conclude with a discussion that revisits the defining role of mutual learning processes in Participatory Design, stressing their important potential contribution to the design of IoT applications. 


\section{BACKGROUND}

We conducted an initial series of 20 scoping interviews with ageing people as part of a larger project about the role of social and tangible technologies in maintaining good habits into old age. Our aims were to learn about our participants and ensure the assumptions and concepts of the research team remained oriented to the experiences of ageing people, including their use of communications, social and tangible technologies. We also sought our participants' interpretations and understandings of what ageing well meant to their own lives and in their own words. The interviews provided a range of insights into ageing people's definitions of 'ageing well', their use of existing internet technologies, and their practices and attitudes around the uptake of new ones (Robertson et al. 2012; 2013). Despite extraordinary diversity in their everyday activities, living situations, use of technology, physical and personal needs, and how these were managed, all participants shared a strong sense of what ageing well meant to them; that is, one that privileged maintaining independence and agency by remaining physically active and well, socially engaged, and contributing actively to their families, social networks and communities. They were remarkably computer literate and willing and able to learn and use technologies that they recognised as useful to them, particularly in relation to central aspects of ageing well, such as maintaining independence, social agency and their ability to remain in their own homes.

Significantly, our participants had little interest in technologies designed specifically for 'the aged'. Instead they wanted to use the same technologies that 'everyone else' used. Some expected these to be designed for use by diverse groups of people without any of the negativity they associated with assistive, age-defined and deficitfocused technologies. These findings informed our decision to investigate whether, and in what ways, the IoT might provide opportunities for interconnected, domestic objects and spaces to support our participants' intentions to maintain their independence, physical and social agency, and participation in their communities for as long as possible. That is, we decided to move away from specific technologies for ageing people and instead work with them to find ways to use emerging IoT technologies to enable domestic environments with attributes, that are not specifically age-related, but could actively contribute to maintaining people's independence and social and physical agency. As one participant commented, "I can see [the project] helping in a very acceptable way long before older people need more intrusive sensors and cameras to enable them to stay in their own home".

\section{EXPLORING WHAT NEEDED TO BE LEARNED}

Having used the findings from the scoping interviews to make decisions about the focus of the next stage of the project, we understood what we needed to learn next from our participants. We needed to be able to link ageing people's understandings of ageing well with how they inhabited their domestic environments in order to embed the design process in their everyday practices. We also needed to learn about our participants' current understandings of, and attitudes toward, internet- connected technologies so we could make decisions about what they needed to learn from us. We anticipated further learning about the use contexts and opportunities for participation through various design workshops and the design of initial prototypes to mediate the processes of co-design.

\section{Interviews and home tours}

A further series of 20 interviews was undertaken with a new cohort of ageing people. For these interviews we sought technology-literate participants who already had, and used, internet connections in their homes. We could then assume some existing knowledge of the internet and its everyday use. These interviews also sought participants' interpretations of what ageing well meant in their own lives, to both confirm the findings of the prior interviews and to act as a bridge between the two series of interviews. However their main foci were aspects of participants' actual domestic environments, the significant objects and spaces within them, and how these were used and inhabited. These interviews included home tours, if offered by participants, and questions to probe participants' existing understandings of, and capacities to envisage, the potentials of densely interconnected objects and environments. The interviews provided rich accounts of our participants' daily activities and the role of objects and specific spatial arrangements in their homes. But there was no evidence in the interview transcripts that our participants could, at this stage, envisage that objects and spaces in their homes might interconnect to act in new and different ways.

Our intention was that the findings from this series of interviews would primarily inform the design of the next stages of the project. We wanted to investigate if and how interconnected objects could be conceptualised by our participants. We were also very conscious that while we had learned a great deal from our participants, we had not yet provided opportunities for them to learn from us, or for the participants and the project team to learn together about the potential of IoT applications to support ageing well. We decided to use a series of probes, both to gather more information about our use situations but also to encourage our participants to specifically focus on different aspects of their domestic activities and environments (Hemming's et al. 2002). We also began to design the first workshop of the project that was intended to further build relationships between the design team and our ageing participants and to enable the co-design of potential scenarios and some simple prototypes.

\section{The workshop}

Resource constraints, especially the time of our participants, meant that our first workshop needed to easily fit within one day. It took several iterations and major redesigns and a smaller, pilot workshop to settle on the final workshop program. Most importantly it was this process of refining what to do in the workshop that made clear (in retrospect) the importance and extent of mutual learning that needed to be achieved in the project. The first iteration of the workshop design was essentially an initial warm up activity followed by a one-day series of lectures in the IoT. The next iteration included shorter lectures plus enough shared design activities to last at 
least a week, including the production of early prototype IoT applications. Design reflection made clear that we needed to think carefully about the outcomes we really needed at this stage and that we were not making sufficient use of the rich accounts in the interviews of our participants' daily activities, or the roles of objects and specific spatial arrangements in their homes. Most importantly, we realised that if we were to genuinely engage our participants, our focus, in designing the next stages of the research, needed to be on the mutual learning process and that this could (and should) continue to inform the desired outcomes of each stage of the research. Of course, we should have been doing this all along! Yet, while mutual learning is assumed and embedded in Participatory Design tools and methods (Kyng 1988; Greenbaum and Kyng 1991, Kensing and Munk-Madsen 1993; Bratteteig 1997; Hansen 2012; Simonsen and Robertson 2013), in hindsight it was only when we explicitly used it as a resource in the overall research design that we could make clear and accountable decisions about how to proceed.

The workshop consisted of two main sessions. The first focused on objects in the home. The nine participants chose a household scenario that had been mentioned by many of those interviewed. Participants identified the objects that might be part of that scenario (plus the walls and floor) and each was asked to enact one of these object's possible behaviours, such as what the object might 'know' that could be useful to people and how other objects might be involved in that scenario. Cards were provided for participants to select if they needed inspiration and these seeded group discussions about how to continue. Enactment (with participants playing the role of an object of choice) proved a valuable way for them to understand that objects might 'know' things and how what they 'knew' could be communicated to and used by other objects (that were also being enacted by other people). Participants could envision small home networks of everyday objects interacting with each other but resisted extending this interaction much beyond the home let alone the wider scale of current visions of the IoT. They could also envisage 'super objects' that could be used for many different functions but these objects were self-contained and did not rely on interconnections.

The second workshop session was a two-part design game focused on areas in and around the home. The nine participants formed three groups of three. Each group chose one of six areas (eg garden, study, kitchen etc). Fifty-six short excerpts from the interview transcripts, describing some every day domestic activity, had been previously selected and had been printed on small cards. In the first part of the game, each group sorted the cards, separating those that suited their chosen space and their current lives from those that did not. Then the suitable cards were arranged into scenarios that made sense to the participants. In the second part of the game each group was assigned one area in the home. This time participants selected cards they considered relevant to their current lives and again arranged these into scenarios they considered feasible. Participants were then assigned a different room and asked to select cards that seemed both possible and desirable in their future lives. Again they were asked to arrange these into scenarios. In both the current and future scenarios participants were asked to explain their rationale for the rejected activities. Participants had no trouble sorting the activities. Overall the workshop produced visions of local networks of objects, some examples of multi-functional objects and a number of scenarios of everyday activities that were strongly focused on their location within the home.

\section{Probes}

Participant observation is difficult in domestic environments (eg Hagen et al. 2005; Bratteteig et al. 2013). As an alternative, a series of probe kits were designed and the first of these distributed at the workshop. One explored ageing people's current uses of information to support their independence and social agency, including information about health and wellbeing, entertainment, self-improvement and social and community engagement. The second probe kit further explored participants' relationships with particular spaces in their homes, probing particularly how and why spaces might be meaningful to them (eg for social interaction or other activities that happened in them or memories that specific objects or spaces provoked). A third sought richer data and located 'snapshots' of actual activities or objects in the home with accounts of the activity from a number of different perspectives.

Early results from the first probe kit reveal the rich ecology of technologies used by people to interact with information. Vivid descriptions of the variety of pull and push activities surrounding information showed that these were often ad hoc. This highlights opportunities for more seamless coordination between different digital technologies. More importantly, we learned more about our participants, such as glimpses of the felt and lived experiences of current technology use, as well as particular hopes and wishes for better ones. Along with the outcomes of the workshop, the probe data will inspire the continuing research design of the project.

\section{DISCUSSION}

Looking back, our project would have greatly benefited from an earlier focus on the setting up of mutual learning processes. Once we had learned more about our participants and realised the limitations of our own and their understandings of emerging IoT technologies we could begin the process of understanding what we needed to learn together and how we would learn it. Most importantly, we could then exploit mutual learning as a resource to focus and support our design thinking and the iterative process of our ongoing research design. It may just be us who needed reminding of the centrality of mutual learning to Participatory Design, but it appears to be less explicitly discussed in PD papers these days.

The rationale for revisiting mutual learning and the setting up of mutual learning processes as the context for this paper is not just to remind us that there are good reasons why mutual learning is a motivation and an outcome "of the Participatory Design heritage" (Kensing and Greenbaum 1993). Our participants' efforts were accompanied by jokes about 'Big Brother' and asides about privacy and security concerns as well as threats of 
intrusive monitoring and gratuitous surveillance. Yet they needed to work very hard to learn to envisage even very small, local arrangements of interconnected objects and spaces. Bratteteig (1997) differentiates between learning enough about technology to suggest and design and enough to develop a technological fantasy and "suggest an application that did not replace old systems or paper based systems but built on the characteristics of computer technology" (p. 9). With great effort most participants learned to do the former but none of us involved in the project have yet learned enough to do the latter.

We suspect that the importance of explicit focus on the mutual learning processes in this project may have been accentuated by the difficulties our participants had to even begin to envisage the massive interconnectivity of the IoT and the enormous technical, social and economic transformations it offers. Though still some way away the promises of the IoT already highlight deep human and moral concerns. Envisaging these transformations in terms of our everyday lives is not trivial and is perhaps not even possible at this stage. Mutual learning looms very large when we reflect on our needs to identify and understand the disruptions (both good and bad) that these emergent technologies bring. We suggest that the IoT promises a shift of a similar scale to the one, initiated by the introduction of computers into workplaces, that inspired the pioneering Scandinavian Participatory Design projects.

Significantly, training was explicitly included in the very early PD projects. Outcomes from the first project, with the Norwegian Iron and Metal Workers' Union (NJMF), included textbooks and vocational training programs on technology (Bjerknes and Bratteteig 1988, p. 4). The Danish DUE project offered a one week course that was attended by up to 500 union members a year for 13 years (Bødker 1988; Kyng 1988) and the Florence project included lectures on computers and databases and as well as topics requested by the nurses (Bjerknes and Bratteteig 1988; Bratteteig 1997). Mutual learning, to establish a common "knowledge platform" for the future work process, was a major part of the early stages of the UTOPIA project; then it was further developed through the innovation of technology laboratories where prototyping and enactment were used to envisage future technologies (eg Kensing and Greenbaum 2013).

Looking back to those projects, we can remember a stage when information technologies were so new, strange and unknown that projects initially and sometimes exclusively focused on enabling people to learn enough about the new technologies to enable them to begin the process of learning to actively engage in their design. Perhaps we are experiencing a similar stage now that requires a similar explicit focus on fundamental participant training and mutual learning processes about another major development of new technologies. Looking forward, the massive interconnectivity between people, things and environments, promised by the IoT, may herald such profound societal change that the urgency of mutual learning and the setting up of mutual learning processes needs to extend well beyond single Participatory Design projects such as the one discussed here. There are new opportunities and urgent imperatives to rethink and foreground opportunities for mutual learning in the Participatory Design of IoT applications.

\section{ACKNOWLEDGMENTS}

This research is partly funded by the Australia Research Council Discovery Grants Program DP110101999. We thank our participants for their contribution.

\section{REFERENCES}

Bjerknes $G$ and Bratteteig, T. User Participation: A Strategy or Work Life democracy. PDC 1988, 3-11.

Bødker, S. Creating condition for participation: Conflicts and resources in system design. PDC 1988, 13-20.

Bratteteig, T. Mutual Learning. Enabling cooperation in systems design. Proc IRIS. Vol. 20. 1997, 1-20.

Bratteteig, T., Bødker, K., Dittrich, Y., Mogensen, P. and Simonsen, J. Methods - Organizing principles and general guidelines for Participatory Design projects. In Simonsen and Robertson (eds. 2013, 117-144.

Greenbaum, J. and Kyng, M. (eds) Design at Work: Cooperative Design of Computer Systems. Lawrence Erlbaum Associates, New Jersey, USA. 1991.

Hagen, P., Robertson, T., Kan, M. and Sadler, K. Emerging Research Methods for Understanding Mobile Technology Use, Proc OZCHI 2005, 1-10.

Hansen, M. A framework for understanding outcomes of mutual learning situations in IT projects. Proc PDC 2012, 2, 97-100.

Hemmings, T., Clarke, K., Rouncefield, M., Crabtree, A., and Rodden, T. Probing the probes. PDC 2002, 42-50.

Kensing, F. and Munk-Madsen, A. PD: structure in the toolbox. Comms. ACM 36, 6. 1993, 78-85.

Kensing, F., and Blomberg, J. Participatory design: Issues and concerns. Computer Supported Cooperative Work (CSCW), 7(3-4), 1998,167-185.

Kensing, F. and Greenbaum, J. Heritage - Having a Say. In Simonsen, J. and Robertson (eds) 2013, 21-36.

Kyng, M. Designing for a dollar a day. CSCW 1988, 178188.

Robertson, T., Durick, J., Brereton, M., Vaisutis, K., Vetere, F., \& Nansen, B. Emerging technologies and the contextual and contingent experiences of ageing well. Proc INTERACT 2013, 582-589.

Robertson, T., Durick, J., Brereton, M., Vetere, F., Howard, S., and Nansen, B. (2012). Knowing our users: Scoping interviews in design research with ageing participants. Proc $\mathrm{OzCHI} 2012$, 517-520.

Robertson, T. and Simonsen, J. Participatory Design: an introduction. In Simonsen and Robertson, 2013, 1-17.

Simonsen, J. and Robertson, T. (eds) Routledge International Handbook of Participatory Design. New York: Routledge, 2013. 